Bangladesh J. Bot. 39(2): 137-141, 2010 (December)

\title{
DIALLEL ANALYSIS OF SEVEN QUANTITATIVE TRAITS IN DESHI JUTE (CORCHORUS CAPSULARIS L.)
}

\author{
RAHIMA KHATUN, RH SARKER ${ }^{1}$ AND MA SOBHAN \\ Bangladesh Jute Research Institute, Dhaka-1207, Bangladesh
}

Key words: Diallel analysis, Inheritance, Dominance effect, Corchorus capsularis

\begin{abstract}
Genetic constitution of yield and its associated traits of Corchorus capsularis L. was investigated using a $10 \times 10$ full diallel cross experiment. Additive gene action system with partial dominance was predominat for plant height, technical height, base diameter and number of nodes in $F_{1}$. Non-allellic interaction was involved in the inheritance of bark weight and stick weight in $\mathrm{F}_{2}$. The $\mathrm{Vr}-\mathrm{Wr}$ graph for bark weight and fibre weight of $F_{1}$ and $F_{2}$ showed an additive genetic system with dominance effect. The parents Acc. 4087 and var. A-38 possessed maximum number of dominant alleles for most of the characters. Acc.1833 possessed an excess of recessive genes for all the characters.
\end{abstract}

\section{Introduction}

Information in relation to the genetic nature of quantitative characters of jute is essential to determine breeding procedure for its varietal improvement. Diallel crosses have been used to obtain information concerning the inheritance of quantitative traits in self-pollinated crops. The analysis of a diallel series of crosses in self-pollinated crops as described by Hayman $(1954,1957)$ and Jinks $(1954,1956)$ has provided the branches with a tool which is of a great value to investigate the genetic control of complex characters. It also enables to make predictions based an early generation which greatly increased the efficiency of a breeding program. Results of diallel cross for yield and yield components in jute have been reported by Jana (1972), Paul et al. (1977) and Srivastava et al. (1979).

Though breeding work has been carried out for yield and its component in jute with the application of the diallel cross, very few workers attempted to include $F_{2}$ in their analysis. The inclusion of $\mathrm{F}_{2}$ may help in distinguishing more complex genetic system that may arise. The present study was thus undertaken with a view to studying the inheritance of the yield contributing characters of jute in $\mathrm{F}_{1}$ and $\mathrm{F}_{2}$ through the diallel cross.

\section{Materials and Methods}

The experimental materials consisted of ten genotypes of deshi jute (Corchorus capsularis L.) including seven new accessions (three were exotic accessions 3695, 1515 and 4087 and four indigenous accessions 1831, 1832, 1833 and 2146) and three improved varieties (CVL-1, A-38 and CC-45). Crosses were made among the genotypes in all possible combinations including reciprocals. Ninety $F_{1} s$ and 10 parents of deshi jute were grown in a randomized complete block design with three replications at the Bangladesh Jute Research Institute in 2001. The plot consisted of one single row of $3.0 \mathrm{~m}$ long with a row to row distance of $30 \mathrm{~cm}$ as well as with plant to plant distance was maintained at $6-7 \mathrm{~cm}$. Similarly, $90 \mathrm{~F}_{2}$ progenies and ten parents were grown at the Central Jute Agricultural Experiment Station (CJAES), Manikganj in 2002. In $F_{1}$ and $F_{2}$ observations were made on 10 randomly selected plants from each row for seven characters plant

${ }^{1}$ Department of Botany, University of Dhaka, Dhaka-1000. Bangladesh.<rhsarker2000@yahoo.co.uk> 
height (m), technical height (m), base diameter (mm), number of nodes, bark weight (g), fibre weight (g) and stick weight (g). The genetic analysis was made following Hayman (1954) and Jinks (1954).

\section{Results and Discussion}

$\mathrm{Vr}$ - Wr graphs for plant height in $\mathrm{F}_{1}$ and $\mathrm{F}_{2}$ are shown in Figs 1 and 2, respectively. In $\mathrm{F}_{1}$ the analysis of all arrays (ten parents) gave a regression of slope $b=+1.0029 \pm 0.0481$ which was significantly different from zero but not from unity indicating absence of non-allelic interaction. The regression line passed through the $\mathrm{Wr}$-axis above the origin indicating partial dominance for this trait. Arrays 2 (3695), 9 (A-38) and 8 (4087) possessed an excess of dominant genes and arrays 3 (1515), 5 (1832) and 6 (1833) possessed an excess of recessive genes. In $F_{2}$, regression coefficient $\mathrm{b}=+0.8272 \pm 0.0996$ differed significantly from zero but not from unity showing absence of non-allelic interaction in both the generations. The regression line passed just below the origin of the Wr-axis indicating over dominance (Fig. 2). Arrays 8 (4087), 10 (CC-45) and 1 (CVL-1) had maximum number of dominant genes. Arrays 5 (1832), 3 (1515) and 6 (1833) had maximum number of recessive genes.

Regarding technical height the value of $b=+1.0082 \pm 0.0618$ of $F_{1}$ differed significantly from zero but not from unity indicating absence of non-allelic interaction. The regression line intercepted the Wr-axis above the origin showing additive gene action with partial dominance (Fig. 3) for this trait. Arrays 9 (A-38) and 4 (1831) possessed an excess of dominant genes while arrays 3 (1515) and 6 (1833) possessed an excess of recessive genes. In $F_{2}$ the regression coefficient $\mathrm{b}=+0.8072 \pm 0.1900$ differed significantly from zero but not from unity showing the absence of non-allelic interaction (Fig. 4). The regression line cut the Wr-axis below the point of origin indicating over dominance for this trait. Arrays 8 (4087) and 9 (A-38) possessed an excess of dominant genes while arrays 2 (3695) and 6 (1833) possessed excess of recessive genes.

The regression coefficient $b=+1.0408 \pm 0.1347$ of base diameter of $F_{1}$ differed significantly from zero but not from unity indicating absence of non-allelic interaction. The regression line passed above the point of origin which indicated the presence of partial dominance for this trait. Arrays 9 (A-38), 8 (4087), and 7 (2146) possessed an excess of dominant genes while arrays 3 (1515) and 6 (1833) had an excess of recessive genes (Fig. 5). In $F_{2}$, the analysis of all arrays (ten parents) gave a regression of slope $b=+0.6199 \pm 0.1275$ which differed significantly both from zero and unity indicating the presence of inter allelic interaction in the inheritance of this trait. The regression line passed below the point of origin which indicated the presence of over dominance (Fig. 6). Arrays 9 (A-38) had an excess of dominant genes and arrays 4 (1831), 5 (1832), 3 (1515) and 6 (1833) had an excess of recessive genes.

The Vr - Wr graphs for number of nodes of $F_{1}$ is shown in Fig. 7. The value of regression coefficient $b=+0.9731 \pm 0.0912$ differed significantly from zero but not from unity indicating the absence of non-allelic interaction for this trait. The regression line cut the $\mathrm{Wr}$-axis above the point of origin which suggested the presence of partial dominance. Arrays 8(4087) had an excess of dominant gene. Arrays 1 (CVL-1), 3 (1515) and 6 (1833) furthest away from the origin possessed an excess of recessive genes. In $F_{2}$ the regression coefficient of $b=+1.0590 \pm 0.1859$ differed significantly from zero but not from unity revealed the absence of non-allelic interaction. The regression line passed below the point of origin indicating over dominance for this trait (Fig. 8). Arrays 5 (1832), 10 (CC-45), 2 (3695), 9 (A-38) and 8 (4087) possessed an excess of dominant genes while arrays 4 (1831), 3 (515) and 6 (1833) furthest away from the origin possessed an excess of recessive genes. 

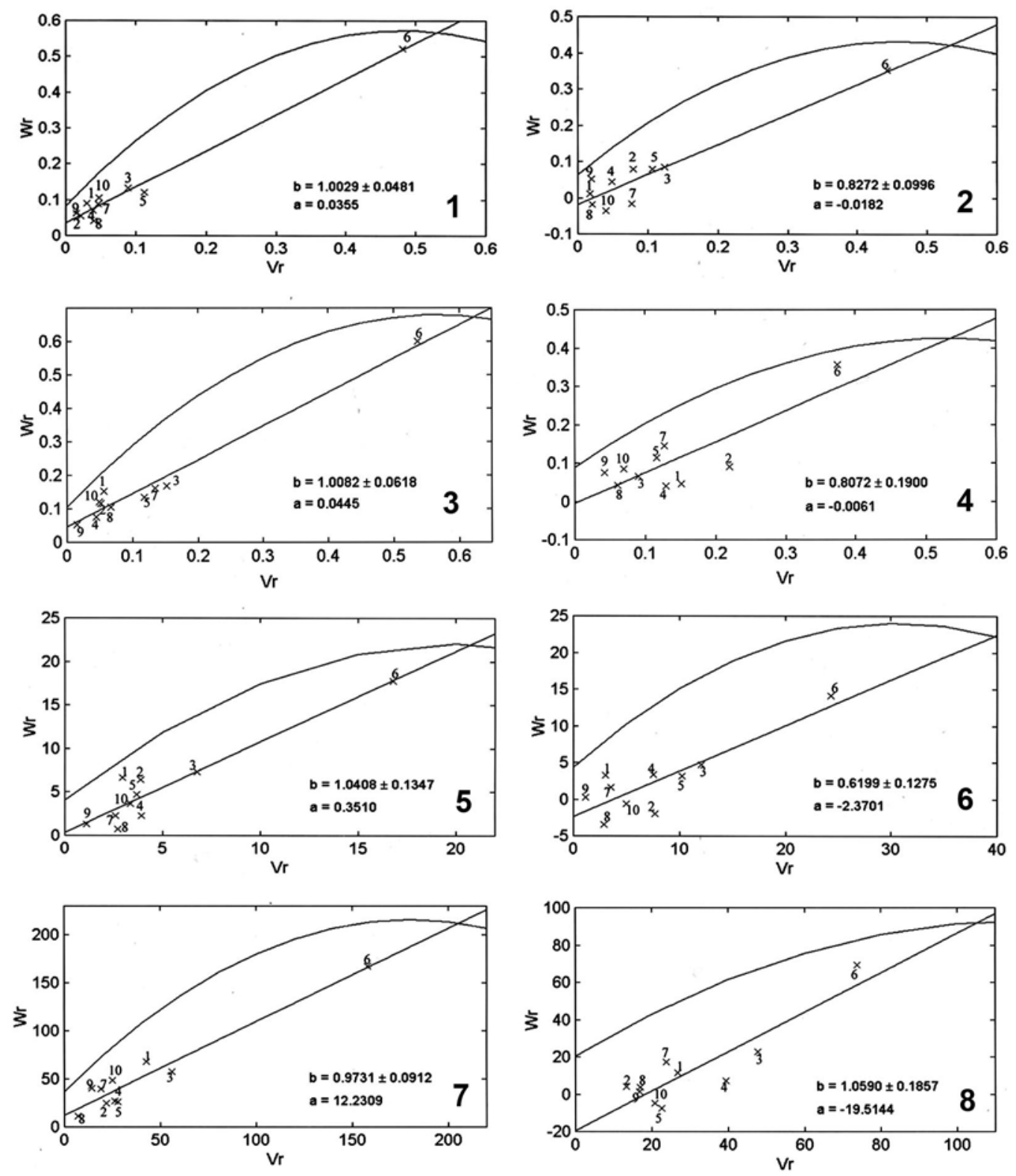

Figs 1-8. $\mathrm{Vr}$ - Wr graphs for different characters of $C$. capsularis: 1 - 2. Plant height $\left(1 . \mathrm{F}_{1}, 2 . \mathrm{F}_{2}\right)$. 3 - 4. Technical height $\left(3 . F_{1}, 4 . F_{2}\right) .5$ - 6. Base diameter $\left(5 . F_{1}, 6 . F_{2}\right) .7$ - 8. Number of nodes $\left(7 . F_{1}, 8 . F_{2}\right)$.

Bark weight of $F_{1}$, the regression coefficient $b=+0.9544 \pm 0.2887$ differed significantly from zero but not from unity indicating absence of non-allelic interaction. The regression line of Wr on Vr passed below the point of origin which indicated the presence of over dominance. Arrays 8 (4087) and 9 (A-38) had an excess of dominant genes and arrays 4 (1831), 10 (CC-45), 1 (CVL-1) and 6 (1833) were furthest from the origin possessed an excess of recessive genes (Fig. 9). In $F_{2}$, for bark weight, the regression coefficient $b=+0.2920 \pm 0.1850$ ) differed significantly from unity 
but not from zero indicating non-allellic interaction. The intersection of regression line on Wr-axis indicated over dominance (Fig. 10). Arrays 3 (1515) and 2 (3695) possessed an excess of dominant genes and arrays 8 (4087), 9 (A-38), 10 (CC-45) and 6 (1833) possessed an excess of recessive genes.

The Vr - Wr graphs for fibre weight of $F_{1}$ are shown in Fig. 11. The analysis of all arrays (ten parents) gave a regression slope $b=+0.7496 \pm 0.2480$ which was significantly different from zero but not from unity indicating absence of non-allelic interaction for this trait. The regression line cut the Wr-axis just below the origin pointed out over dominance effect. Arrays 8 (4087), 9 (A-38) and 3 (1515) had an excess of dominant genes while arrays 1 (CVL-1) and 6 (1833) possessed an excess of recessive genes. In $F_{2}$, the regression co-efficient $b=+0.5803 \pm 0.2072$ was significantly different from zero but not significantly different from unity indicating absence of non-allelic interaction in the inheritance of fibre weight. The observed regression lines intercepted the Wr-axis just below the origin indicating over dominance (Fig.12). Arrays 8 (4087), 3 (1515) and 9 (A-38) had an excess of dominant genes while arrays 6 (1833) and 4 (1831) possessed an excess of recessive genes. The $\mathrm{Vr}-\mathrm{Wr}$ regression analysis of $\mathrm{F}_{1}$ and $\mathrm{F}_{2}$ showed close similarity with each other.
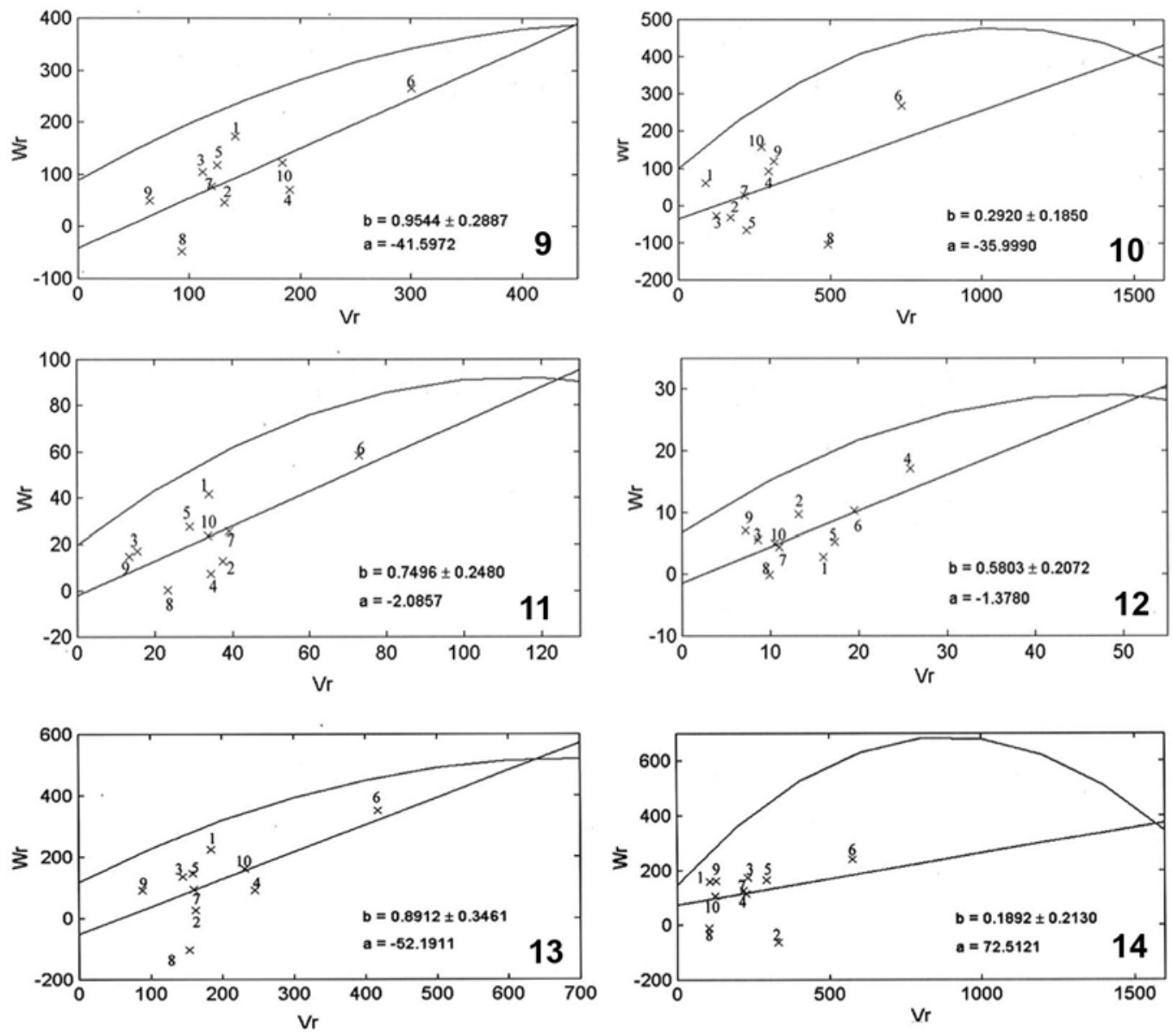

Figs 9-14. Vr - Wr graphs for different characters of $C$. capsularis: 9-10. Bark weight $\left(9 . \mathrm{F}_{1}, 10 . \mathrm{F}_{2}\right) .11-12$. Fibre weight $\left(11 . \mathrm{F}_{1}, 12 . \mathrm{F}_{2}\right) .13$ - 14. Stick weight $\left(13 . \mathrm{F}_{1}, 14 . \mathrm{F}_{2}\right)$. 
The Vr - Wr graphs for stick weight of $\mathrm{F}_{1}$ are shown in Fig.13. The analysis of all arrays (ten parents) gave a regression of slope $b=+0.8912 \pm 0.3461$ which was significantly different from zero but not from unity indicating the absence of non-allelic interaction.The regression line cut the $\mathrm{Wr}$-axis below the point of origin which indicated the presence of over dominance. Arrays 8 (4087), 9 (A-38) and 2 (3695) possessed an excess of dominant genes. And arrays 4 (1831), 10 (CC-45), 1 (CVL-1) and 6 (1833) furthest away from the origin possessed an excess of recessive genes. In $F_{2}$ regression coefficient $b=+0.1892 \pm 0.2130$, which was not significantly different from zero but it was significantly different from unity indicating the presence of non-allelic interaction (Fig. 14). The regression line cut the $\mathrm{Wr}$-axis above the point of origin showing partial dominance for this trait. Arrays 8 (4087) and 10 (CC-45) had an excess of dominant genes and arrays 3 (1515), 5 (1832), 2 (3695) and 6 (1833) had an excess of recessive genes.

The distribution of array points indicated that $\mathrm{P}_{8}(4087)$ and $\mathrm{P}_{9}(\mathrm{~A}-38)$ possessed a maximum number of dominant alleles for most of the characters in $F_{1}$ and $F_{2}$ whereas array 6 (1833) possessed highest number of recessive alleles for all the characters with exception to fibre weight in $\mathrm{F}_{2}$.

The genetic control of the characters in terms of the additive and non-additive genetic effects was estimated with the help of Vr - Wr regression graphs. Exposition of the nature of gene action for different traits is an important prerequisite in predicting the effectiveness of selection in a population for the improvement of yield in commercially important crop (Mandal and Choudhury 1986). It provides a clear information regarding genetic architecture of parents. In $F_{1}$ and $F_{2}$ results revealed that sufficient genetic diversity existed among the parents, which is essential for the improvement of a crop. Those parents located near the origin of the regression line possessed an excess of dominant genes for the particular character and those furthest away from the origin possessed an excess of recessive genes. In this respect the parent behaved differently in different characters. The location of array points in the graph in relation to all the characters showed that no parents were completely heterozygous that indicated by Dickinson and Jinks (1956). Under such situation simple selection would not be effective for improvement in the present genetic population. The reciprocal recurrent selection which can exploit fixable as well as non-fixable gene action would be the most suitable selection procedure.

\section{References}

Dickinson AG and JL Jinks 1956. A generalized analysis of diallel crosses. Genet. 41: 65-78.

Hayman BI 1954. The theory and analysis of diallel crosses. Genet. 39: 789-809.

Hayman BI 1957. Interaction, heterosis and diallel crosses. Genet. 42: 336-355.

Jana MK 1972. Genetic analysis of some quantitative traits in jute. Ph.D. Thesis, Kalyani University, Kalyani.

Jinks JL 1954. The analysis of continuous variation in a diallel cross of Nicotiana rustica varieties. Genet. 39: 767-788.

Jinks JL 1956. The $F_{2}$ and backcross generations from a set of diallel crosses. Heredity 10: 1-30.

Mandal AB and TG Choudhury 1986. Combining ability in tossa jute. Bangladesh J. Jute Fib. Res. 11(1\&2): $7-11$.

Paul NK, OI Joarder and AM Eunus 1977. Gene action, heterosis and combining ability for some quantitative characters of jute (Corchorus olitorius L.). J. Bangladesh Acad. Sci. 1: 43-52.

Srivastava SK, BP Pandey and RSL Srivastava 1979. Diallel analysis of characters governing fibre yield in white jute. Indian J. Agric. Sci. 49: 153-163. 